\title{
A model of spatially evolving herpesvirus epidemics causing mass mortality in Australian pilchard Sardinops sagax
}

\author{
Alexander G. Murray ${ }^{1,2, *}$, Michael O'Callaghan ${ }^{3}$, Brian Jones ${ }^{4}$ \\ ${ }^{1}$ Fisheries Research Services Marine Laboratory, Victoria Road, Torry, Aberdeen AB11 9DB, Scotland, United Kingdom \\ ${ }^{2}$ Department of Zoology, University of Aberdeen, Tillydrone Avenue, Old Aberdeen AB24 2TZ, Scotland, United Kingdom \\ ${ }^{3}$ Inland Mathematics Research Network, North Street, Eugowra, New South Wales 2806, Australia \\ ${ }^{4}$ Fisheries Western Australia, PO Box 20, Perth, Western Australia 6020, Australia
}

\begin{abstract}
In 1995 mass mortality of pilchards Sardinops sagax occurred along >5000 km of Australian coast; similar events occurred in 1998/99. This mortality was closely associated with a herpesvirus. The pilchard is an important food source for larger animals and supports commercial fisheries. Both epidemics originated in South Australian waters and spread as waves with velocities of 10 to $40 \mathrm{~km} \mathrm{~d}^{-1}$. Velocity was constant for a single wave, but varied between the epidemics and between the east- and west-bound waves in each epidemic. The pattern of mortality evolved from recurrent episodes to a single peak with distance from the origin. A 1-dimensional model of these epidemics has been developed. The host population is divided into susceptible, infected and latent, infected and infectious, and removed (recovered and dead) phases; the latent and infectious periods are of fixed duration. This model produces the mortality patterns observed locally and during the spread and evolution of the epidemic. It is consistent with evidence from pathology. The wave velocity is sensitive to diffusion coefficients, viral transmission rates and latent period. These parameters are constrained using the local and large-scale patterns of epidemic spread. The relative roles of these parameters in explaining differences between epidemics and between east- and west-bound waves within epidemics are discussed. The model predicts very high levels of infection, indicating that many surviving pilchards recovered following infection. Control appears impracticable once epidemics are initiated, but impact can be minimised by protecting juvenile stocks.
\end{abstract}

KEY WORDS: Epidemic $\cdot$ Model $\cdot$ Herpesvirus $\cdot$ Mass mortality $\cdot$ Pilchard $\cdot$ Australia

\section{INTRODUCTION}

Mass mortalities due to epidemic disease can be spectacular and powerful phenomena that can suddenly disrupt the functioning of ecosystems and damage biodiversity (Daszak et al. 2000). Such mass mortalities are reported with increasing frequency and affect a wide variety of marine organisms, ranging from algae to mammals (Harvell et al. 1999). Economic losses due to emerging marine epidemic diseases may also be very large, particularly in aquaculture (Hill 2002), and diseases also interact with wild-capture fisheries (Dobson \& May 1987). It is therefore of great value to understand the processes that drive these epidemics, particularly epidemics of emerging diseases. Here we describe a detailed model of the spread in Australian waters of a particularly spectacular epidemic disease that caused mass mortality of pilchards, a fish of considerable ecological and economic significance.

In March 1995 vast numbers of dead pilchards Sardinops sagax started to wash up on beaches along the central South Australian coast (Whittington et al. 1997). Over the next 3 mo, mass mortalities spread west and east to cover over $5000 \mathrm{~km}$ of temperate and subtropical coastline, the entire Australian range of 


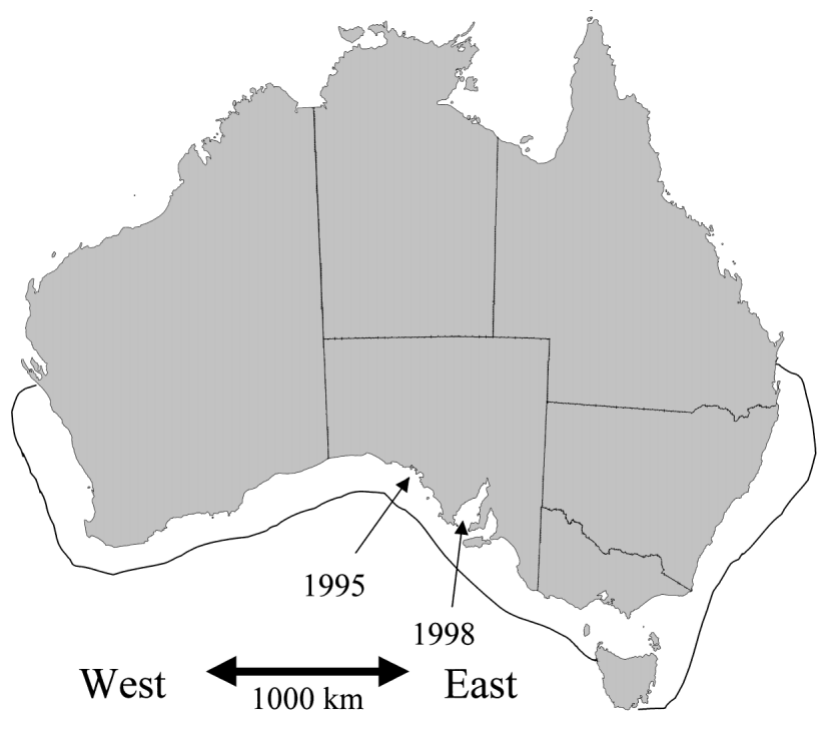

Fig. 1. Sardinops sagax. Map of the distribution of the pilchard in Australian waters (after Fletcher et al. 1997). Also shown are the locations where mortality was first detected in the 1995 (western Eyre Penisula) and 1998/99 (Spencer Gulf) epidemics

this species. The mortality occurred as a locally shortlived outbreak, forming waves that travelled at very high and near-constant velocities. Mortality also occurred from June in New Zealand (Smith 1995). The outbreak was unprecedented in scale for an observed epidemic (Gaut 2001), although Californian sedimentary records imply collapses have occurred over the centuries (Baumgartner et al. 1992). The scale of mortality provided a generally clear picture of the spread of the epidemic.

In November 1998 a second occurrence of such mass mortality events began (Gaughan et al. 2000). Mortality spread over the same area, again starting in South Australia, but at about half the velocity of 1995. Hence this epidemic lasted for over 6 mo, although again the duration at most localities was brief. On this occasion New Zealand was not affected. Mortality, however, was probably even greater than during the 1995 epidemic.

No features of the physical environment (Griffin et al. 1997) or unusual or toxic algae (Fletcher et al. 1997) were associated with the 1995 mass mortality events. There is also no evidence of any environmental linkage in 1998/99. The only common feature of the mortality events was herpesvirus in lesions of the gills of sick fish up to $4 \mathrm{~d}$ before mortality occurred (Whittington et al. 1997). Only pilchards were affected, other tested fish proving negative to herpesvirus (Gaut 2001), and only indirect impacts on other animals were recorded (Dann et al. 2000). The virus has not been successfully transmitted experimentally (Gaut 2001, B. Jones unpubl. data), and so Koch's postulates have not formally been fulfilled. This is not unusual for diseases of wild fish, even in well studied species like salmon (Bakke \& Harris 1998). The pattern of pilchard mortality was that of the classical epidemic, and other hypotheses that have been investigated have been rejected (Fletcher et al. 1997, Griffin et al. 1997). The virus plays a direct role in the mortality of pilchards, although other factors may influence the level of mortality.

The epidemic spread with a remarkably high velocity; speeds varied between the 1995 and 1998/99 epidemics and between the east- and west-bound waves within these epidemics, but velocity was near constant within such a wave. In 1995, the east-bound epidemic wave travelled at nearly $40 \mathrm{~km} \mathrm{~d}^{-1}$; other waves travelled at lesser but still impressive $\left(>10 \mathrm{~km} \mathrm{~d}^{-1}\right)$ speeds. The upper velocities begin to approach the pilchards' swimming speed; required diffusion coefficients can, however, be generated by pilchard swimming behaviour (see Murray et al. 2001a).

The pattern of mortality evolved as the epidemics matured; the pattern and its evolution were similar for both epidemics. Initially mortality events occurred repeatedly in and around the position of the first outbreak in South Australia. Later, a single distinct mortality wave developed with the mortality at any one location occurring over, at most, a few days.

The pilchard is an abundant fish in temperate Australian shelf waters (Fig. 1). Being planktiverous it forms a critical link in the food chain, consuming both phytoplankton and zooplankton (Van der Lingen

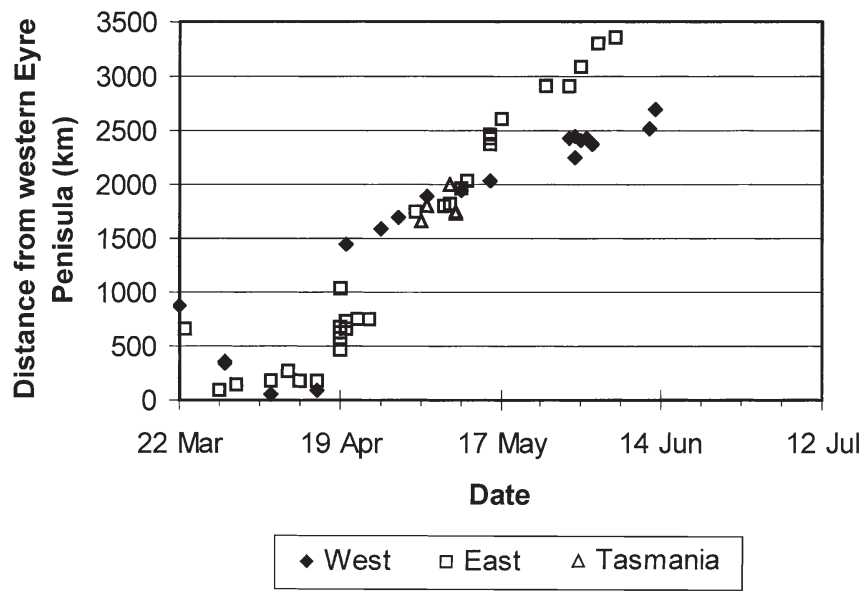

Fig. 2. Sardinops sagax. Location of recorded mortality versus time in 1995. Location is the minimum distance travelled from the western Eyre Penisula, the point of origin of the 1995 epidemic. Derived from data supplied by CSIRO. $x$-axis labels are at 4 wk intervals 


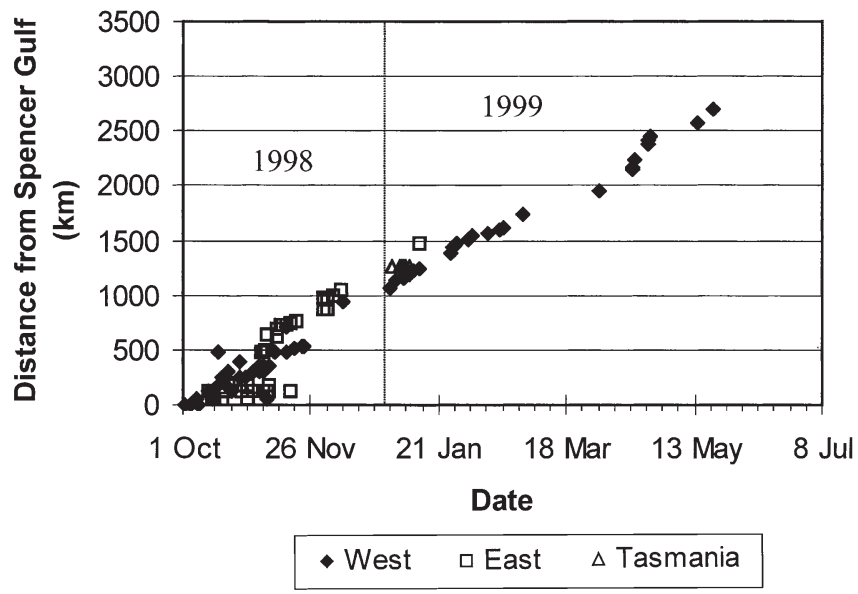

Fig. 3. Sardinops sagax. Location of recorded mortality versus time in 1998/99. Location is the minimum distance travelled from Spencer Gulf, the point of origin of the 1998/99 epidemic. Derived from data supplied by the Australian state fisheries authorities. $X$-axis labels are at $8 \mathrm{wk}$ intervals

1998), and itself being food for a large range of other fish, birds and mammals (Gaughan et al. 2000). Pilchards also support local fisheries in the states of Victoria, South Australia and Western Australia (Fletcher 1992, Neira et al. 1999); economic damage to fisheries of the 1995 epidemic has been estimated as A \$12 M (Daszak et al. 2000). The epidemic therefore has important ecological and economic implications.

\section{MATERIALS AND METHODS}

A model of the epidemic. Modelling is a powerful means of analysing the epidemiology of diseases (Anderson \& May 1979), allowing determination of the mechanisms behind the spread of mortality and analysis of potential control strategies. Modelling requires good data to validate the model developed.

Data. The most useful data sets that are available for the purpose of modelling consist of the reports of the time and locations of mass mortality events of pilchards. Off Australia the pilchard is largely restricted to the coastal shelf, which is narrow relative to its length, so their distribution is essentially 1-dimensional (Fig. 1). This enabled distance travelled by the epidemic from its origin to be calculated. Distances were found from the minimum marine distances between neighbouring mass mortality events, which were summed to give the total distance from the point of origin. Earlier analysis looked at the absolute distance from the origin (Murray 2001a); when the epidemic waves were not travelling due east or west, estimates of distance became distorted, and hence this method was not used to estimate wave speed. Plots of time versus distance from the origin for mortality reported during the 1995 (Fig. 2) and 1998/99 epidemics (Fig. 3) are presented.

The epidemics spread at a remarkably constant rate and showed very little scatter about the regression line, demonstrating both the constant speed of the front and the brief local duration of mortality. Velocities of east- and west-bound waves of an epidemic differed. We estimated the 1995 wave velocities as $36 \mathrm{~km}$ $\mathrm{d}^{-1}$ east-bound and $22 \mathrm{~km} \mathrm{~d}^{-1}$ west-bound (Murray et al. 2000). The 1998/99 epidemic showed wave velocities of 20 and $10.7 \mathrm{~km} \mathrm{~d}^{-1}$ east- and west-bound, respectively. However there is more uncertainty in the east-bound wave's velocity in this case because the epidemic disappeared, only to reappear off northern New South Wales and southern Tasmania, respectively, $100 \mathrm{~s}$ of $\mathrm{km}$ north-east and south-east of the previous report in Victoria.

The pattern of persistence of mortality evolved as the epidemic matured. Mortality persisted, or recurred, at the point of origin for a period of weeks. However, in the mature epidemic, persistence was for a few days or less. We illustrate this change by plotting the time between the first and last records of mortality along $250 \mathrm{~km}$ stretches of coast (Fig. 4). The duration in any one area, in 1995, declines from about $30 \mathrm{~d}$ at the origin to around $5 \mathrm{~d}$ at greater distances from the origin: more formally persistence is 69.6 to $8.41 \mathrm{ln}$ (km from origin) $d, r^{2}=0.86$. Since the mature epidemic is travelling at about $30 \mathrm{~km} \mathrm{~d}^{-1}$, the persistence at distance is due to the passage of the wave across $250 \mathrm{~km}$. The 1998/99 epidemic follows a similar evolutionary pattern to 1995. But the relative change in wave speed was less (34.6 to $11.4 \mathrm{ln}$ [km from origin], $\mathrm{r}^{2}=0.34$ ) because the wave travelled less rapidly, leading to

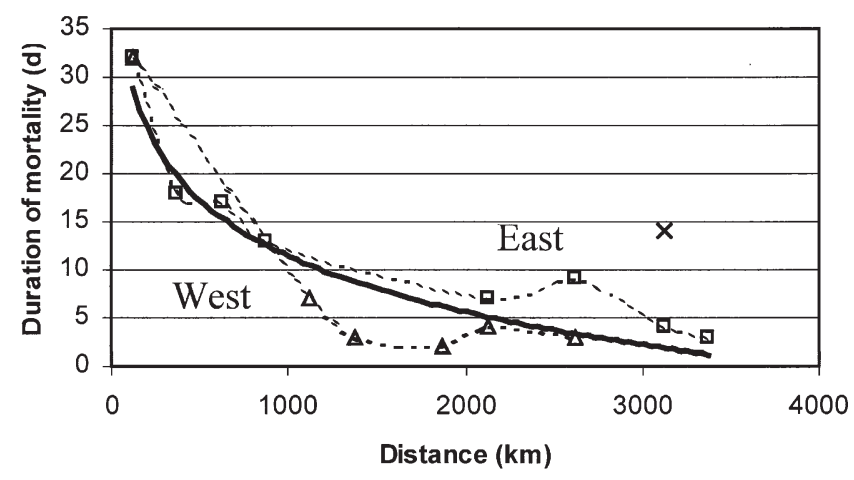

Fig. 4. Sardinops sagax. Days that mortality persisted in local $250 \mathrm{~km}$ interval versus distance from the point of origin of the 1995 epidemic. The log regression line, $-8.41 \mathrm{ln}(\mathrm{km}$ from origin) +69.6 , has an $r^{2}$ of 0.86 . $\square$ : west-bound; $\Delta$ : east-bound; $\times$ : a western data point excluded because a single mortality event occurred $10 \mathrm{~d}$ after other mortality events in the area 
longer persistence of mortality at a distance from the origin. Also, the east-bound wave was only intermittently detectable after the eastern Bass Strait, some $1400 \mathrm{~km}$ from the origin (Fig. 3), leading to fewer data being available at distance from the origin.

An example of the local pattern of mortality under the mature wave is that obtained from reports of dead pilchards in the south-eastern area of Tasmania (Fig. 5). We see that $50 \%$ of all reports applied to a single day and that, with 1 exception, the mortality was only reported over a $5 \mathrm{~d}$ period.

Pathology provided further data. Pilchards developed lesions up to $4 \mathrm{~d}$ before deaths occurred (Whittington et al. 1997). These lesions changed in character as the time of mortality approached, so the gap between lesions occurring and mortality is not some artefact caused by undetected low initial levels of mortality. The pilchards only exhibited signs of stress a few minutes before dying (Whittington et al. 1997) allowing infected and uninfected fish to school together. A related observation was a large decline between 1995 and 1998/99 in the number of lesions in the gills of dying fish (AAHL 1999). This indicates a decline in viral release and hence in the viruses available for transmission to new hosts; this observation is important in itself and as a reminder that the details of the infection (and hence model parameters) are not necessarily constant.

Data on pilchard movements have also been used to constrain the diffusion coefficient (Murray et al. 2000, 2001a). We used this data to show that fish movement was capable of producing diffusion coefficients that are consistent with the observed passage of the epidemic. We have excluded vectors from the modelling (see 'Discussion').

More detailed descriptions of these and other data that were used in parameter derivation, and in the pro-

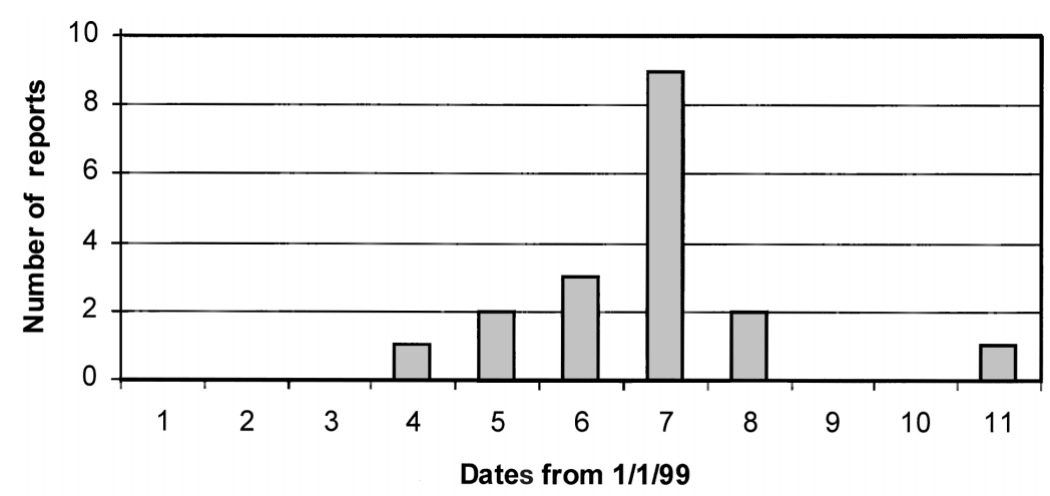

Fig. 5. Dates for which dead pilchards Sardinops sagax were reported by the public in south-eastern Tasmania in January 1999. Data supplied by Tasmanian Department of Primary Industry cess of model development and validation, are provided in Murray et al. (2000).

The model. We have already used simple models to analyse the epidemic's basic properties (Murray et al. 2001a). The models used are based on the approach of Anderson \& May (1979). We divide the population up into susceptible $(S)$, infected but latent $(E)$, infected and infectious $(I)$, and removed $(R)$ components. The last group, $R$, includes both the recovered (immune) and dead fractions of the pilchard population. The fate of $R$ is unimportant to the propagation of the epidemic, but obviously controls the epidemic's longer-term impacts.

Simple models, with continuous turnover, fail to fully describe the development of the disease following infection. Viral-filled lesions appeared up to $4 \mathrm{~d}$ prior to the occurrence of mortality (Whittington et al. 1997). Infection cannot have occurred after the lesions formed and may have occurred even earlier. Under the simple models mortality starts to occur immediately following infection (Murray et al. 2001a). This is not realistic; following infection a pathogen's numbers must take time to build up before it can spread to other hosts or kill its existing host.

The simple model also rapidly and smoothly produces an infection with a single peak of mortality and does not show the evolution from the recurrent mortality observed near the origin to the single short-lived peak that is observed at greater distances from the origin.

We therefore have developed a model that does have these properties. The model is base on fixed durations, rather than turnover rates, of the stages of the epidemic. This approach has been used to model the outbreak of disease in populations of moths (Dwyer \& Elkington 1993).

The model was implemented in a 1-dimensional spatial structure, taking advantage of the essentially linear distribution of the Australian pilchard (Fig. 1). Equations used the well established form of the diffusion equation (Fisher 1932, Murray et al. 2001a), with dispersal depending upon a diffusion coefficient, $D$, and the gradient in variable concentration. See Table 1 for all abbreviation definitions.

The partial differential equations, including the spatial component, are:

$$
\begin{aligned}
\partial S / \partial t & =-\beta I S+D^{2} S / \partial x^{2} \\
\partial E / \partial t & =\beta I S+X_{x, t-b}+D^{2} E / \partial x^{2} \\
\partial I / \partial t & =X_{x, t-b}-X_{x, t-c}+D^{2} I / \partial x^{2} \\
\partial R / \partial t & =X_{x, t-c}+D^{2} R / \partial x^{2}
\end{aligned}
$$


Once infection occurs the fate of the infected individuals is fixed (Fig. 6). Fish in the latent phase of infection $(E)$ persist in that state for $b$ days, while the infectious phase $I$ is occupied for $c-b$ days, after this they either recover or die. In the absence of diffusion $(D=0)$ the value of $X$ in Eqs. (1) to (4) depends simply upon the values of $I$ and $S$ at location $x$ at a time $\tau$ before the present time $t$. (Eq. 5a). However, with diffusion the number of individuals at location $x$ that were infected at time $\tau$ is analytically complicated because of the movements of fish following infection (Eq. $5 b$ ).

$$
\begin{gathered}
X_{x, \tau}=\beta I_{x, \tau} S_{x, \tau} \\
X_{x, \tau}=\beta \int_{-\infty}^{\infty} \frac{\frac{-(x-y)^{2}}{2 D t-\tau}}{2 \sqrt{\pi D t-\tau}} I_{y, \tau} S_{y, \tau} \mathrm{d} y
\end{gathered}
$$

Fortunately Eq. (5b) is not solved explicitly; it emerges implicitly as a result of the solution of diffusion of $E$ - and $I$-phase individuals during the maturation of infection. Numerical issues involved in the implementation of this model are discussed elsewhere (Murray et al. 2000, 2001b).

Modelled viral transmission is proportional to the product of the densities of infectious and susceptible individuals in the population ( $\beta I S)$. This is a standard approach in epidemiology (Anderson \& May 1979). Because population density plays only a small role in determining wave velocity (see 'Results: Wave velocities' parameter sensitivity'), and populations did not differ much between 1995 and 1998/99 (Ward et al. $2001 b)$, we cannot distinguish between a densitydependent $(\beta I S)$ and density-independent $(\beta I S /[S+I+R])$ models (Murray et al. 2000). Actual transmission reflects the mixing of fish between and within schools (Murray et al. 2001b).

The appropriate form of the diffusion equation for large-scale dispersion in this model is discussed elsewhere by Murray et al. (2001a).

To aid analysis we have developed an analytical method of deriving the mature epidemic's wave velocity for a version of the model with a fixed latent period length (O'Callaghan \& Murray 2002). This method has also been shown to apply to models with fixed infectious-period length in the region of parameter space appropriate for these epidemics (Murray et al. 2000).

\section{RESULTS}

\section{Wave velocities' parameter sensitivity}

The velocity of the epidemic's spread is the bestcharacterised property of the epidemic and so the most

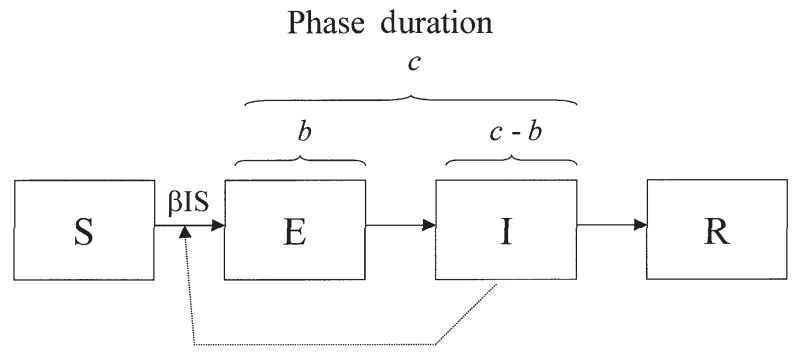

Fig. 6. Structure of the model used to describe the development of the pilchard Sardinops sagax herpesvirus epidemics at a location. The model consists of susceptible $(S)$, infected but latent $(E)$, infected and infectious $(I)$, and removed $(R)$ phases. Infection (both $E$ and $I$ phases) persists for time $C$, incu-bation

$(E)$ for time $b$, and the infectious phase $(I)$ for time $c-b$

profitable area for analysis. We have used both the dynamic model discussed above and its analytical solution (O'Callaghan \& Murray 2002) to map sensitivity of the wave velocity to parameters. Like the wave velocity of rabies in models that incorporate a latent period (Yachi et al. 1989), the wave velocity under this model is dependent upon the diffusion coefficient, transmission rate, population density and latent-period length (O'Callaghan \& Murray, 2002). The exact parameter sensitivity does differ from the continuous turnover model (Fig. 7a,b,c).

The model exhibits least sensitivity to the infection transmission rate $\beta$, provided that this is $>1 \mathrm{~d}^{-1}$. As will be discussed, high transmission rates are required to reproduce the observed peak of mortality (Fig. 5). In spite of the lack of sensitivity of wave speed to this parameter, it may have varied by orders of magnitude, and so could have changed wave velocity between epidemics. A major reduction in lesion frequency in

Table 1. Parameters and variables used in the models. Note that pilchard Sardinops sagax hosts are normalised to a standard population density such that $\mathrm{n}=1$

\begin{tabular}{|lll|}
\hline Parameter & \multicolumn{1}{c|}{ Description } & Unit \\
\hline$D$ & Diffusion coefficient & $\mathrm{km}^{2} \mathrm{~d}^{-1}$ \\
$\beta$ & Transmission rate & $\mathrm{host})^{-1} \mathrm{~d}^{-1}$ \\
$b$ & Length of latent period $E$ & $\mathrm{~d}$ \\
$C$ & Total length of infection $(E$ and $I)$ & $\mathrm{d}$ \\
$C-b$ & Length of infectious phase $(I)$ & $\mathrm{d}$ \\
$t$ & Time & $\mathrm{d}$ \\
$\tau$ & A time before $t(t-b$ or $t-C)$ & $\mathrm{d}$ \\
$\mathrm{X}_{\mathrm{y}, \mathrm{t}}$ & Infection at $y$ after time $t$ & Hosts \\
Variables & & \\
$S$ & Susceptible hosts & Hosts \\
$E$ & Latent hosts & Hosts \\
$I$ & Infectious hosts & Hosts \\
$R$ & Removed hosts (recovered + dead) & Hosts \\
\hline
\end{tabular}


infected fish between 1995 and 1998 (AAHL 1999) argues for substantial change in $\beta$.

Wave speed responds with similar weakness to changes in population density. Biomass changed relatively little between the epidemics (Murray \& Gaughan 2003) and so differences in population sizes did not play a significant role in the differences between epidemics.

The wave velocity is shown to be proportional to the square root of diffusion - as are epidemic wave velocities generated by simpler models (Murray et al. 2001a),
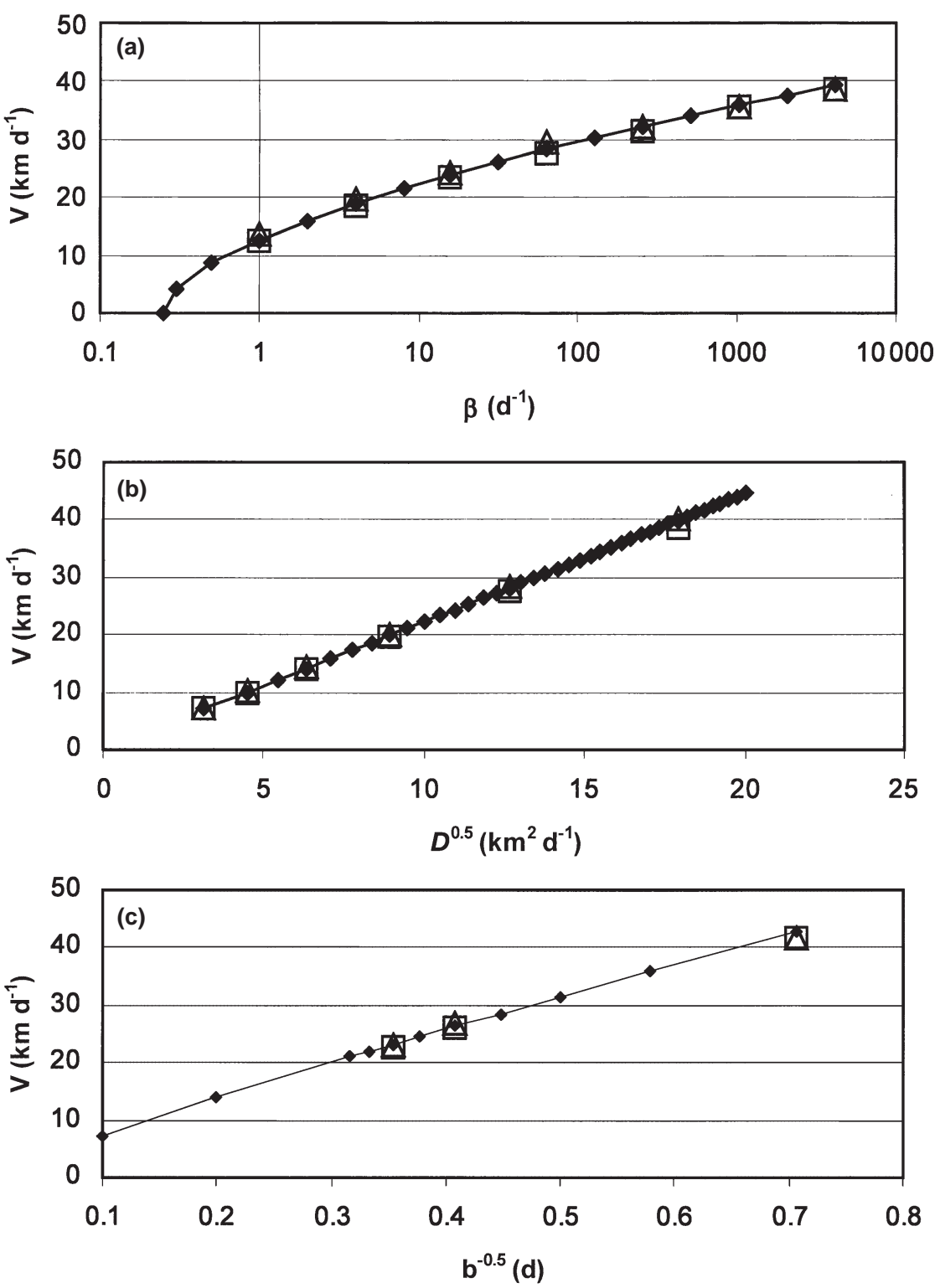

Fig. 7. Sensitivity of epidemic wave velocity to (a) infection transmission rate $\beta$, (b) the square root of diffusion coefficient $(D)$, and (c) the inverse square root of the latent period $b$. Analytical solution ( $\bullet$, numerical solution fixed latent period ( $\square$ ) and fixed latent period plus fixed infective period $(\Delta)$ or indeed the Fisher equation (Fisher 1932). We have estimated limits to this parameter with reference to observed pilchard behaviour (Murray et al. 2001a). Values of up to $1000 \mathrm{~km}^{2} \mathrm{~d}^{-1}$ are possible and values of 100 to $400 \mathrm{~km}^{2} \mathrm{~d}^{-1}$ are easily generated, based on observed pilchard speeds and behaviour. Much higher values can be generated by bird-based dispersal, but we later show that values greater than about 200 to $400 \mathrm{~km}^{2} \mathrm{~d}^{-1}$ are inconsistent with the epidemic's behaviour.

The third parameter controlling the wave's velocity is the length of the latent period. The wave speed varies with the inverse square root of latent-period length. This is a far greater sensitivity than in the continuous turnover version of the model, whose wave speed varies with the inverse 4th root of period length (Yachi et al. 1989).

\section{A maximum diffusion coefficient value}

In the mature wave, mortality persists for only a very short period at any given location (Figs. 4 \& 5). This rapid turnover requires that the production of new infections locally plays a large role relative to dispersion in the progress of the epidemic wave. If diffusion plays too a large role, the wave becomes elongated and that means the mortality occurs over a long period at any given location. Using the observed short duration of local mortality we can constrain $D$ for the observed epidemic waves' velocities.

We use a wave velocity of $40 \mathrm{~km}$ $\mathrm{d}^{-1}$ to approximate the east-bound 1995 wave, $20 \mathrm{~km} \mathrm{~d}^{-1}$ for the westbound 1995 and east-bound 1998/99 waves, and $10 \mathrm{~km} \mathrm{~d}^{-1}$ for the westbound 1998/99 wave. For 2 given values of the 3 critical parameters $(\beta, b$ and $D$ ), we can calculate the third to produce this wave velocity. We then solve the model numerically and sample output at $1500 \mathrm{~km}$ to allow the mature wave to form (the model was also sampled at 500 and $1000 \mathrm{~km}$ to ensure the wave had matured).

For a fixed diffusion coefficient of $200 \mathrm{~km}^{2} \mathrm{~d}^{-1}$, the model is used to generate a wave velocity of $40 \mathrm{~km} \mathrm{~d}^{-1}$ for 
latent periods of $1,2,3$ and $4 \mathrm{~d}$ by selecting appropriate infection rates (Fig. 8). The wave shape does not vary with latent period length because for a given value of $D$ the slope of the spatial gradient in 1 must be constant if the wave velocity is to be kept constant. Hence the shape of the wave of infection is similar for a particular wave velocity at a given $D$, regardless of the other parameters.

If the diffusion coefficient is altered, while holding the latent period at $1 \mathrm{~d}$ and maintaining the wave velocity, again by altering $\beta$ (Fig. 9), the shape of the wave changes substantially: as $D$ increases the wave becomes more elongated. Instead of a peak of 1 or $2 \mathrm{~d}$ of relatively high mortality, several days of very similar levels of mortality occur. When $D=50 \mathrm{~km}^{2} \mathrm{~d}^{-1}$, most mortality occurs in $1 \mathrm{~d}$ and $80 \%$ occurs over a $2 \mathrm{~d}$ period. As $D$ increases from 100 to $200 \mathrm{~km}^{2} \mathrm{~d}^{-1}$, the period over which $80 \%$ mortality occurs rises from about 3 to $4 \mathrm{~d}$ and $50 \%$ of mortality still occurs in less than $2 \mathrm{~d}$, which is still consistent with observations (Fig. 5). However when $D=400 \mathrm{~km}^{2} \mathrm{~d}^{-1}$ mortality is spread over several days, and this is inconsistent with observations.

The 1995 west-bound wave and the 1998/99 eastbound wave travelled at about $20 \mathrm{~km} \mathrm{~d}^{-1}$. This is consistent with $D<150 \mathrm{~km}^{2} \mathrm{~d}^{-1}$ (Murray et al. 2000). The west-bound wave in 1998/99 travelled at a little over $10 \mathrm{~km} \mathrm{~d}^{-1}$, this is consistent with $D$ of up to only about $30 \mathrm{~km}^{2} \mathrm{~d}^{-1}$ (Murray et al. 2000). These $D$ values can easily be generated by fish swimming patterns and without recourse to vectors (Murray et al. 2001a).

\section{Diffusion coefficient and latent period co-constraints}

As infection transmission rate becomes large, the epidemic wave velocity ceases to respond to further increases in this parameter (Fig. 7a). Thus wave velocity becomes effectively a function only of diffusion coefficient and latent period. From this, for a given diffusion coefficient $D$ and epidemic wave velocity, there is a given latent period. Since we have a maximum $D$ value, there is also a maximum latent period.

We present results for the $40 \mathrm{~km} \mathrm{~d}^{-1}$ wave velocity (Fig. 10). We have established that maximum $D$ is 200 to $>400 \mathrm{~km}^{2} \mathrm{~d}^{-1}$, which gives a maximum latent period of about 4 to $<8 \mathrm{~d}$ as $\beta$ becomes large. Similar analysis (Murray et al. 2000) found latent periods of up to about $8 \mathrm{~d}$ are compatible with the $20 \mathrm{~km} \mathrm{~d}^{-1}$ wave and of $12 \mathrm{~d}$ with the $10 \mathrm{~km} \mathrm{~d}^{-1}$ wave. If a $4 \mathrm{~d}$ latent period applies to all the waves then $D=50$ and $12.5 \mathrm{~km}^{2} \mathrm{~d}^{-1}$ for the 20 and $10 \mathrm{~km} \mathrm{~d}^{-1}$ waves respectively.

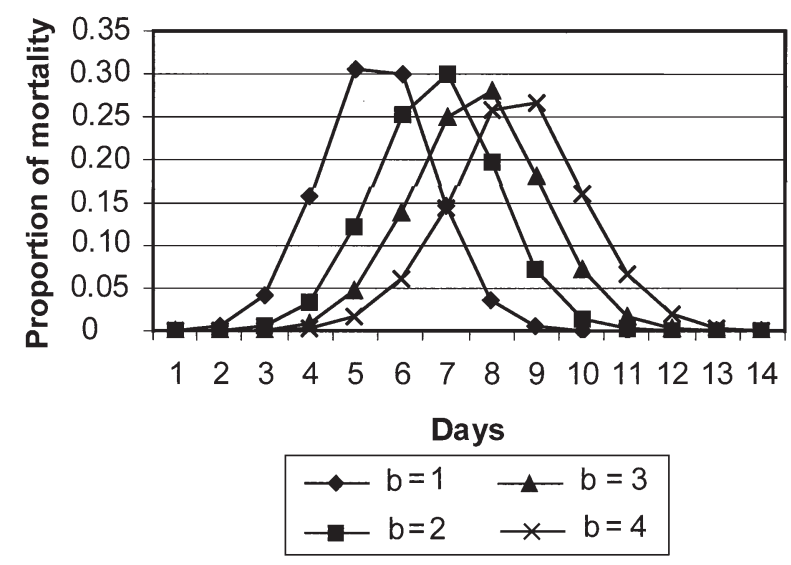

Fig. 8. Distribution of Sardinops sagax mortality over time for a $40 \mathrm{~km} \mathrm{~d}^{-1}$ wave at a point (1500 $\mathrm{km}$ from origin) for model runs with the diffusion coefficient $(D)=200 \mathrm{~km}^{2} \mathrm{~d}^{-1}$. Runs have been executed with latent periods of 1, 2, 3 and $4 \mathrm{~d}$ length. The infectious phase $(I)$ of length $c-b=4 \mathrm{~d}$, and infection transmission rate $(\beta)$ values of $13.9,102,750$ and $5527 \mathrm{~d}^{-1}$ give the $40 \mathrm{~km} \mathrm{~d}^{-1}$ velocity

\section{Temporal evolution of the epidemic wave and minimum latent period}

The epidemic matures from recurrent mortality over weeks at the origin, to a very short-lived single mortality event distant from the origin. This evolution can be replicated by the fixed phase-length model, but not by continuous turnover models.

This pattern of an evolving wave is generated if latent periods, $b$, are longer than infectious periods, $c-b$. If the latent period is relatively long, then initially several peaks of mortality occur because disease is

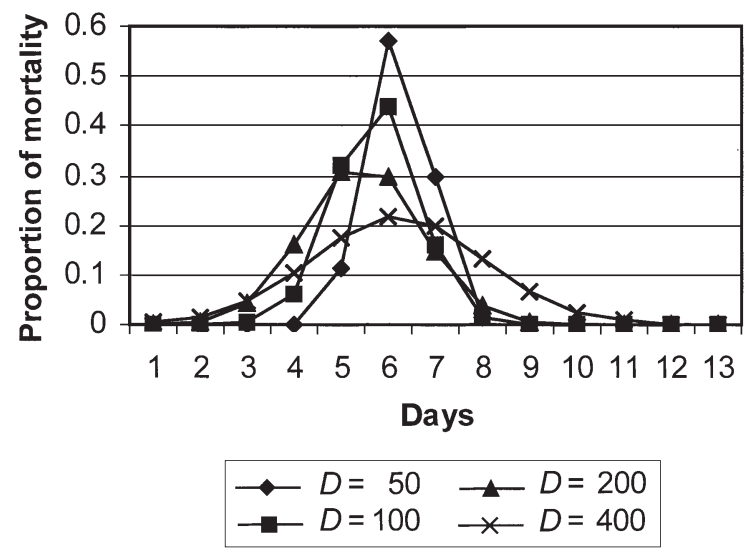

Fig. 9. Distribution of Sardinops sagax mortality over time for a $40 \mathrm{~km} \mathrm{~d}^{-1}$ wave at a point (1500 km from origin) for model runs with latent period of $1 \mathrm{~d}$ and diffusion coefficients $(D)$ of $50,100,200$ and $400 \mathrm{~km} \mathrm{~d}^{-1}$. The infectious phase (I) of length $c-b=4 \mathrm{~d}$ and and infection transmission rate $(\beta)$ values of $2945,123,13.9$ and $3.24 \mathrm{~d}^{-1}$ giving the $40 \mathrm{~km} \mathrm{~d}^{-1}$ velocity 


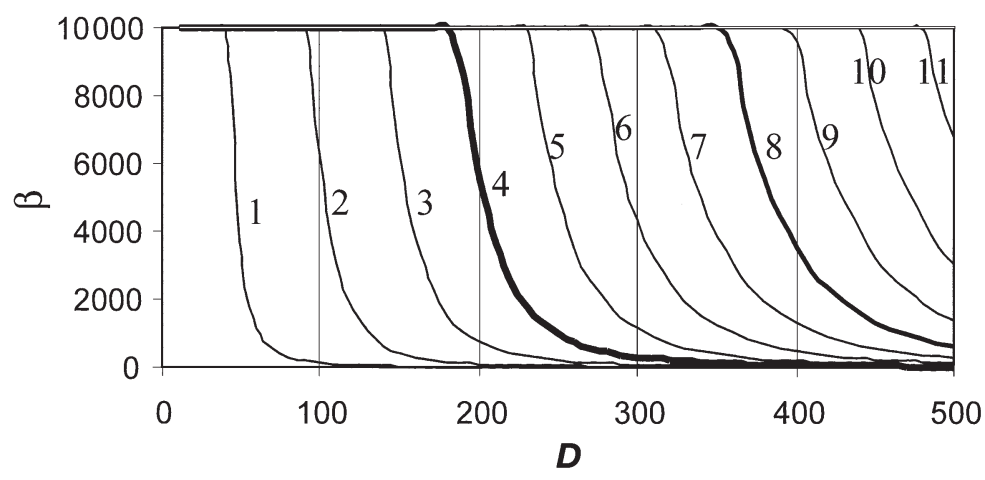

Fig. 10. Values of infection transmission rate $(\beta)$ and diffusion coefficient $(D)$ required to generate wave velocities of $40 \mathrm{~km} \mathrm{~d}^{-1}$ for latent periods $(b)$ of 1 to $11 \mathrm{~d}$ ( $4 \mathrm{~d}=$ treble line, $8 \mathrm{~d}=$ double line)

spread during the infectious period before the first outbreak of mortality. Mortality ceases during the latent period while these new infections develop, then a second period of mortality occurs. This leads to a second round of infection, and so on. If the latent period is short, then the mortality events overlap and so the mortality occurs as a single peak. This evolution is illustrated using the mortality occurring at the epidemic's origin, $500 \mathrm{~km}$ from the origin and $1000 \mathrm{~km}$ from the origin under models with 1 and $5 \mathrm{~d}$ latent periods (Fig. 11). In the former there are only small differences between the epidemic waves at these locations; in the latter the epidemic evolves from initial multiple outbreaks to an increasingly coalesced single wave.

Unlike the behaviour of the mature wave, wave evolution depends upon initial conditions. A moderately large initial infection is required; otherwise multiple infection cycles may occur before mortality becomes ap-

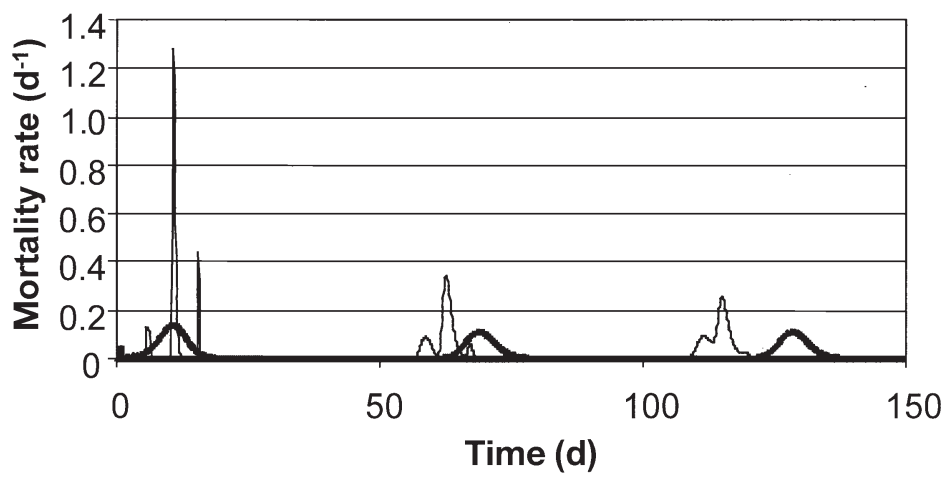

Fig. 11. Development with time of Sardinops sagax mortality waves at 0,500 and $1000 \mathrm{~km}$ from the point of origin of the epidemic. Thick line $=$ $1 \mathrm{~d}$ latent period, thin line $=5 \mathrm{~d}$ latent period. These mortality waves have a peak mortality rate at around $10 \mathrm{~d}$ (origin), $70 \mathrm{~d}(500 \mathrm{~km})$ and $120 \mathrm{~d}(1000 \mathrm{~km})$ parent. These repeated infection cycles lead to the waves coalescing before being detected.

\section{Infection and mortality}

Estimates of mortality due to the 1995 epidemic vary from 10 to $15 \%$ of the population in Western Australia (Fletcher et al. 1997) to $60 \%$ in South Australia (Ward et al. 2001b). Mortality estimates for $1998 / 99$ are again of ca. 60 to $70 \%$ (Gaughan et al. 2000). However, the model runs produce infection levels that are over $90 \%$ and often approaching $100 \%$ for reasonable parameter values (Table 2). A short infectious period of $1 \mathrm{~d}$ is used to give a conservatively low estimate of levels of infection; if the infectious period is longer than this, then infection levels may be even higher than in Table 2 . The faster epidemic waves of 1995 produce higher modelled levels of overall infection, but show less mortality than in 1998/99. This difference between levels of infection and mortality means that a crucial factor in the impact of the epidemic is the fraction of the population that recovers from infection; avoidance of infection appears to account for a much lower proportion of the post-epidemic population.

Table 2 also shows how the rapid spread of infection requires that infection rate $\beta$ be greater than 3 to 5 host $^{-1} \mathrm{~d}^{-1}$ under realistic diffusion coefficients and latent periods.

Viruses were either absent from all fish or were detected in a very high proportion (75 to $100 \%$ ) of examined fish (Whittington et al. 1997). This pattern is consistent with the modelled infection, but sampling was limited and not systematic.

Only 10 out of 400 fish in sea cages survived the passage of the epidemic, a mortality rate of $97.5 \%$ (B. Jones unpubl. data). However, causes of mortality were not well characterised, so some of these fish could have died of secondary infection brought on by the stresses of being caged with dead pilchards. The surviving pilchards had lesions, indicating that they had survived, rather than avoided, infection.

\section{DISCUSSION}

\section{The model}

The pilchard herpesvirus epidemics were particularly suitable for modelling. The occur- 
Table 2. Levels of infection of pilchard Sardinops sagax obtained under model conditions used to generate wave velocities of 10 , 20 and $40 \mathrm{~km} \mathrm{~d}^{-1}$. Latent period is $4 \mathrm{~d}$. Infectious period length is $1 \mathrm{~d}$ to minimise infection. Maximum values of $D$ consistent with observed mortality patterns are shown in bold

\begin{tabular}{|c|c|c|c|c|c|c|c|c|}
\hline \multicolumn{3}{|c|}{$10 \mathrm{~km}$} & \multicolumn{2}{|r|}{$20 \mathrm{~km}$} & \multirow[b]{2}{*}{ Infection (\%) } & \multirow[b]{2}{*}{$D$} & \multirow{2}{*}{$\begin{array}{c}-40 \mathrm{~km} \\
\beta\end{array}$} & \multirow[b]{2}{*}{ Infection (\%) } \\
\hline$D$ & $\beta$ & Infection (\%) & $D$ & $\beta$ & & & & \\
\hline 10 & 32.58 & 100.00 & 50 & 18.57 & 100.00 & 50 & 3213 & 100.00 \\
\hline 20 & 7.31 & 99.56 & 100 & 5.18 & 98.07 & 100 & 144 & 100.00 \\
\hline 30 & 4.08 & 95.61 & 150 & 3.17 & 90.53 & 200 & 18.57 & 99.99 \\
\hline 50 & 2.44 & 81.22 & 200 & 2.44 & 81.14 & 400 & 5.18 & 98.03 \\
\hline
\end{tabular}

rence of mass mortality resulted in large numbers of bodies being washed onto beaches, which provided a clear indicator of the spread of the disease in space and time. These events were reported by the public even where no official system had been established. The short duration (or rapid passage) of mortality allowed the model to dispense with details of the pilchards' life cycle such as recruitment or mortality due to predation. The distribution of the pilchards in the Australian coastal shelf meant that the spread was essentially 1-dimensional and the distance the epidemic had travelled from the origin to any mortality event (whose time could be recorded) was clear. The 2 epidemics spread in 2 directions giving 4 replicates, which allows investigation of the parameter sensitivity of the epidemic. Pilchard mortality occurred in stocks that were preparing to breed, had already bred, or were within the process of breeding within a single epidemic (Fletcher et al. 1997), and at all times of year without any apparent effect on that epidemic's rate of propagation.

Spatial modelling has previously been successfully applied to only a few epidemics of wildlife. Examples are phocine distemper virus among seals (Swinton et al. 1998), whose bodies are relatively easily detected, and rabies whose human health and economic costs has led to collection of plentiful data suitable for spatial modelling, particularly of fox rabies (Yachi et al. 1989). Diseases have been modelled non-spatially in fish populations, both in general terms (Dobson \& May 1987) and for specific diseases such as Icthyophonus in herring (Paterson 1996). However, here we have had adequate data to develop and test a spatially explicit model of an epidemic in a commercially exploited wild fish population.

This model is one of several used to analyse the epidemic. We have used a similar model to look at spread at the school level (Murray et al. 2001b), and we have used simplified models for initial analysis of the epidemic and as a means of assessing the roles of basic processes (Murray et al. 2001a). We have also adapted this model to investigate the effects of more process formulations than can be covered here, e.g. non-linear transmission (Murray et al. 2000). A model of the population's post-epidemic recovery has also been developed (Murray \& Gaughan 2003). In other words, we do not seek to design an all inclusive model, but rather our models are designed to be appropriate to our various tasks and the available data.

An analytical means of deriving the velocity of the wave generated by the model has also been produced (O'Callaghan \& Murray 2002). This is used for analysis of the wave velocity's parameter sensitivity and to aid in the analysis process of the numerical model by ensuring that parameter combinations used will generate wave velocities that are consistent with observations.

Our approach differs from the standard model in our use of fixed-length latent and infectious periods. There are 3 sets of parameters that the model's epidemic wave velocity shows sensitivity to. These are infection transmission rate (and population density), diffusion coefficient and latent period length. This is a similar pattern of parameter sensitivity of wave velocity to that obtained under continuous turnover models, such as rabies (Yachi et al. 1989), but differs in details of this sensitivity, particularly (not surprisingly) to the latent period to which the wave's velocity sensitivity declines from a square-root to 4th-root relationship.

Vectors have been excluded from the model. To replicate the local development of the epidemic we must constrain the diffusion coefficient to a range of values $\left(<400 \mathrm{~km}^{2} \mathrm{~d}^{-1}\right)$ that can be generated by pilchard swimming speeds and patterns (Murray et al. 2001a), i.e. a bird or other vector of transmission is not required. The slower wave speeds are only consistent with $D<30 \mathrm{~km}^{2} \mathrm{~d}^{-1}$. Negative PCR tests on seabird faeces (Gaut 2001) and a lack of transmission to juvenile pilchards (Whittington et al. 1997), which suggests mixing of fish between schools, is required for transmission (Murray et al. 2001b); both support this lack of a role for vectors. Patterns of spread do not fit those generated by anthropogenic vectors (Murray et al. 2002).

Even if vectors are generally unimportant, it is possible that they played a role in the origin of the epi- 
demics, as large numbers of seabirds were observed feeding on pilchards fed to caged tuna (Bayly 2002). Both epidemics originated in a relatively small area of South Australia, where caged tuna were fed on imported pilchards (Gaughan 2002). There was, however, some scatter in 1995 in the earliest reported 2 reports of mortality (Fig. 2). This could reflect oceanographic transport of dead fish before they washed ashore: with only 2 data points, chance may have played a role. The origin used in Figs. 2 \& 3 does not affect the slope of the line at points distant from that origin, and therefore does not affect estimated wave speed. The point selected was approximately at the centre of the initial scatter for 1995, which also corresponds to where most subsequent events were reported over the next month, and is probably, therefore, the true point of origin. With less scatter in 1998 the point of origin was clearer.

We have used the patterns generated by the local and geographical development of the epidemic to develop constraints on parameter ranges and relationships. We have also used the evolution of the pattern of mortality to develop parameter constraints, particularly on the latent period for which experimental constraints are lacking.

The constraints on $D$ can be used to constrain the latent period length $b$ to a maximum of 4 to $12 \mathrm{~d}$, depending upon the epidemic wave's speed. The initial behaviour of the epidemic suggested $b>2 \mathrm{~d}$. Tighter experimentally obtained constraints on this parameter would strongly constrain the model. Some fish must move the full distance of the epidemic's spread during the latent period, at least $36 \mathrm{~km} \mathrm{~d}^{-1} \times b$ (probably 150 to $200 \mathrm{~km}$ in 1995). However, if $\beta$ is large, only a small number of fish need move the full distance, a distance which pilchards are certainly capable of (Torres et al. 1984).

The infection rate $\beta$ is weakly constrained, being limited to values greater than about 3 to 5 host $^{-1} \mathrm{~d}^{-1}$. This means that during the initial development of the epidemic at a location, when most pilchards are still susceptible to infection $(S \approx 1)$, the average infected fish infects at least 3 to 5 fish $\mathrm{d}^{-1}$, and probably many more.

This model differs from continuous turnover models in that the epidemic evolves from recurrent events spread over weeks to a single locally short-lived event. This feature has not been described in other epidemics, possibly because epidemic behaviour at the point of origin is rarely so well documented as in this case. The evolution of the epidemic's nature occurs because different cycles of infection and latency are discrete. This feature constrains the infectious period $(c-b)$ to a period less than the latent period $b$. In a less virulent epidemic, which required a larger number of cycles to develop to the point of causing detectable mortality, these cycles would merge before the mortality was even detected.

Koi carp Cyprinus carpio infected with koi herpesvirus have a histopathology almost identical to that of pilchard herpesvirus. The fish develop lethargy and nervous signs about $4 \mathrm{~d}$ post infection and die 3 to $4 \mathrm{~d}$ after onset of signs. Mortality following experimental bath infection is 80 to $100 \%$ (Hedrick et al. 2000). These data suggest that the parameters derived for pilchard herpesevirus from this model are not unreasonable.

\section{Differences between and within epidemics}

The wave velocities in the 2 epidemics, and between the east- and west-bound waves within epidemics, were different. Since the wave velocity is controlled by 3 parameters we can consider their relative roles to explain the observed differences.

Physical transport may have contributed to difference between east- and west-bound waves, but is unlikely to be the cause of difference between wave velocities in the different directions (Griffin et al. 1997, Murray et al. 2000). The south coast of Australia is swept by an eastbound current, and it is conceivable that a $10 \mathrm{~km} \mathrm{~d}^{-1}$ east-bound current, together with a $30 \mathrm{~km} \mathrm{~d}^{-1}$ epidemic wave, would give overall propagation of $20 \mathrm{~km} \mathrm{~d}^{-1}$ west and $40 \mathrm{~km} \mathrm{~d}^{-1}$ east, as observed in 1995. A $5 \mathrm{~km} \mathrm{~d}^{-1}$ current and $15 \mathrm{~km} \mathrm{~d}^{-1}$ wave would give the 10 and $20 \mathrm{~km}$ $\mathrm{d}^{-1}$ waves of $1998 / 99$. However, there are several problems with the idea that the wave was driven by eastward advection. This would imply that pilchards were constantly moving east, which could not be true indefinitely and does not accord even in the short term with localised populations (Yardin et al. 1998). It is possible that sick pilchards drifted east, while healthy ones did not, but pilchards were not observed to show behavioural changes until shortly before death (Whittington et al. 1997). The currents are highly variable (Griffin et al. 1997) and the epidemics propagated through storms (Fletcher et al. 1997); if there was passive drift, the regressions of epidemic spread would be expected to be much more variable than observed. Lack of variation within years is especially surprising if the current speed was a different constant during the 2 epidemics. The current along the east coast of Australia is south-bound, and therefore the eastward spread of mortality should slow down on reaching the east coast, yet there is no sign of this in the data (Griffin et al. 1997).

We may account for differences between waves by differences in behaviour of the pilchards in the west and the east. This can change $D$ by changing largescale movements, but may also alter $\beta$ at the population level due to local changes in schooling (Murray et 
al. 2001b). In the west, pilchards live in distinct populations in small regions (Edmunds \& Fletcher 1997), meaning there is limited mixing and hence low diffusion coefficients. Off eastern Australia, pilchard migrated north to mate in winter (Ward \& Staunton-Smith 2002) and so are far more mobile. Yardin et al. (1998) noted a high degree of mixing in south eastern pilchard stocks and their distribution varied with time (Neira et al. 1999). There are also regional differences in pilchard life spans, $6 \mathrm{yr}$ in the east and $8 \mathrm{yr}$ in the west (Fletcher 1992), which supports the concept of different pilchard lifestyles. The pattern of mortality was highly consistent in the west between epidemics (Murray et al. 2000), but in the east the location of mortality varied between epidemics, e.g. there was mortality on the north coast of Tasmania in 1995, but not 1998/99, which also argues for mobile fish stocks. In 1998/99 the epidemic was only irregularly apparent on the east coast. If dispersal were higher along that coast then the peak mortality could be reduced, leading to a lack of detection as scavengers removed bodies as quickly as they were produced. In other words, we are arguing that pilchards on the east coast behave differently from those on the west coast - this has implications for the locally appropriate scale of fisheries management.

Differences in population density between east and west could cause small differences in wave speed. However, sensitivity to population differences is very low and densities are likely to be higher in the west since most of the fisheries are in this area. The size of schools into which the population is subdivided may lead to differences in $\beta$ at the population level (Murray et al. 2001b). It is conceivable that the more mobile schools found in the east are larger than those in the west. We lack data on school sizes, but the weak sensitivity of wave speeds to this parameter means that there is unlikely to be any major effect of differences in local school sizes.

Transmission parameters $\beta$ or $b$ could change due to evolution of the pathogen. While viral evolution may be rapid (Ebert 1998), we would not expect major differences between 2 waves within an epidemic for this reason, given there is little variation within those waves.

Between the epidemics there is more time for viral evolution, and hence it is possible that the $\beta$ and $b$ parameters varied; the surviving fish may also be disease-resistant, which could further change these parameters' values. Indeed it seems certain that $\beta$ did decrease given the far lower number of lesions present in gills of infected fish during the second epidemic (AAHL 1999). If $\beta$ alone changed, this could not account for the observed changes between the epidemics, because, for a given latent period and diffusion coefficient, the higher wave velocities $\left(40 \mathrm{~km} \mathrm{~d}^{-1}\right)$ cannot be made consistent with the slowest $\left(10 \mathrm{~km} \mathrm{~d}^{-1}\right)$ just by changing $\beta$. So the latent period must have increased, or the diffusion coefficient decreased, or both. We have no direct evidence on alteration of either parameter, but 1995 was the end of an El Niño and was associated with lower coastal productivity (Neira et al. 1999); hence it is possible pilchards had to forage over larger distances. Pilchards do move longer distances along the South American coast during El Niño years (Torres et al. 1984).

The model shows a role for changes in diffusion coefficients between, as well as within, the 2 epidemics. The maximum diffusion coefficient consistent with the $10 \mathrm{~km} \mathrm{~d}^{-1}$ wave is $30 \mathrm{~km}^{2} \mathrm{~d}^{-1}$; if $D$ is 4 times this for the east-bound wave (as discussed for differences between waves in a single epidemic) we obtain $D=$ $120 \mathrm{~km}^{2} \mathrm{~d}^{-1}$. We can see however, that this value of $D$ is only consistent with latent periods of up to $2 \mathrm{~d}$ duration if we use it to generate a $40 \mathrm{~km} \mathrm{~d}^{-1}$ wave (Fig. 10). Lesions are already visible up to $4 \mathrm{~d}$ before mortality occurs (minimum length of infection), which means with a 2 day latent period the infectious period would be at least $2 \mathrm{~d}$ long. But the latent period should be longer than the total infectious period to generate appropriate initial epidemic patterns. Therefore $D$ must have been greater than $120 \mathrm{~km}^{2} \mathrm{~d}^{-1}$ in the eastbound wave in 1995 . Hence $D$ differs between as well as within epidemics.

Modelling analysis of the epidemic gives us a new source of information on the nature of pilchard movements (Murray et al. 2001a, 2001b). It suggests that mixing is much stronger in the east than in the west and that the boundaries between local and regional populations are extremely porous. The easy mixing between populations does not lead to such strong genetic mixing because different populations have different locations and times of breeding, which leads to reproductive separation. The pattern is consistent with genetic evidence, which shows distinct but overlapping populations (Yardin et al. 1998), as does isotope evidence (Edmonds \& Fletcher 1997). Differences in behaviour may be less if there is eastward advection, but this is unlikely to be a major factor in differences in epidemic spread (Griffin et al. 1997). This mixing pattern implies that specific fish stocks should define management areas, which should be managed in collaboration with neighbouring areas, and that a larger spatial scale for management may be needed in the east than in the west.

\section{Impact and mitigation of the epidemics}

Mortality levels were typically estimated at 60 to $75 \%$ of the population (Gaughan et al. 2000, Ward et 
al. 2001a,b) and mortality of 10 to $15 \%$ was estimated in Western Australia for 1995 (Fletcher et al. 1997). Juvenile pilchards were vulnerable to the diseases (at least in 1998) but only locally showed mass mortality (Ward et al. 2001b).

Mortality inflicted by disease interacts with other forms of mortality, such as fishing (Dobson \& May 1987). In some cases fishing could reduce epidemic mortality if the population was reduced towards the threshold for epidemic transmission (Dobson \& May 1987). This does not appear to be the case for pilchards because a very high proportion of the population was infected (Table 2) and very low transmission thresholds observed (Murray et al. 2001b). Survivorship is controlled more by recovery post-infection than by epidemic thresholds.

The high efficiency of disease transmission means that control of the epidemic, once established, is almost impossible; the epidemic rages until virtually no susceptible individuals are left to support it. The very weak sensitivity to population density means that policies based on population reduction (such as 'firebreaks') are unlikely to succeed. Due to the latent period, infection occurs several days before death. Given the observed front velocities, this means that controls would have to be implemented several hundred $\mathrm{km}$ beyond the apparent front. We can also say that control of vectors, such as birds, is unlikely to have any significant impact on the epidemic. These are significant, if negative, results of the modelling.

In 1995 mortality of 10 to $15 \%$ of the pilchard population was estimated to have occurred in Western Australia (Fletcher et al. 1997), whereas in 1998/99 mortality was $70 \%$ in that state (Gaughan et al. 2000). Perhaps a long-term defence is to introduce a strain of the virus that inflicts low levels of mortality ahead of a virulent epidemic. This immunisation approach has formidable practical difficulties and would require detailed safety assessment before any application, but theoretically it allows for a very large reduction in mortality.

Juvenile pilchards did not generally suffer from mass mortality, although at least in 1998 juvenile pilchards locally died from the disease, indicating they are not inherently resistant. This restricted mortality may be due to the weak mixing of juvenile pilchard stocks, which live in isolated populations in individual bays (Neira et al. 1999).

So far, the pilchard population has recovered rapidly from the mortality events (Ward et al. 2001b), probably because of the low mortality of juvenile stocks (Murray \& Gaughan 2003). Pilchard growth is food-limited (Gaughan et al. 2001) and so can increase at a lower population (competition) density. Japanese pilchards have recovered from much larger perturbations brought about by recruitment failure (Heath et al. 1998).
In the longer term, pilchard mortality could lead to replacement by other species. A large increase in the egg and larval biomass of the anchovy Engraulis australis occurred following the epidemics (Ward et al. 2001a), and such changes could lead to the long-term replacement of pilchards by anchovies as has been observed off California (Baumgartner et al. 1992).

Secondary effects on consumers have been relatively limited, notably increased mortality and reduced recruitment of little penguins (Dann et al. 2000). Gannets, whose diet was dominated by adult pilchards, switched their diet to anchovy, and while recruitment was reduced, adult starvation was avoided (Bunce \& Norman 2000). Other effects on consumers are documented by Gaut (2001).

\section{CONCLUSIONS}

We present a model which describes the local and large-scale spread of an epidemic of herpesvirus that caused widespread mass mortality of pilchards in Australian waters. The model uses fixed length periods to describe the latent and infectious stages of infection. This produces an epidemic that evolves from episodic mortality over a period of weeks, to a single short-lived mortality peak as the epidemic spreads away from its point of origin. This pattern accords with the observed epidemiology and pathology of the infection.

The epidemic wave's velocity is strongly constrained by the observations of mortality. It depends upon the diffusion coefficient, transmission rate and the length of the latent period. The effect of variation in population density is probably very small. Vectors such as birds or ships do not appear to play a major role in the spread of the epidemic.

The model has been used to analyse variation between the epidemics and between the east- and west-bound waves of each of the epidemics. In both epidemics the east-bound wave is twice the velocity of the west-bound wave. This argues for a diffusion coefficient 4 times greater in the east; therefore eastern pilchards are probably more mobile. The model also indicates changes in diffusion coefficient, which may explain differences in velocity of the 2 epidemics. The epidemics took place at different times of year, and in 1995, under El Niño conditions, this may have led to differences in fish behaviour. The disease also changed, with fewer lesions and higher mortality estimates for 1998/99 than for 1995. The model could be strongly constrained if more data were available on the latent periods during the 2 epidemics.

The model predicts levels of infection that are much higher than the estimated levels of mortality. This difference indicates that some infected pilchards do 
survive. Juvenile populations have largely avoided mortality and play a major role in population recovery, so the conservation of juvenile fish and their environment will help to speed the recovery of pilchards, should the epidemic return.

Acknowledgements. This work was funded by FRDC grant 99/225. We would like to thank the CCEAD Joint Pilchard Scientific Working Group for its support, and especially its first chairman Gary Morgan for encouraging the application of modelling to the pilchard epidemics. Stephen Walker of CSIRO and Geoff Gordon of NSW Fisheries provided support for the setting up of the study. Numerous scientists, and members of the public, from 6 states provided the data that were used in developing and testing this model.

\section{LITERATURE CITED}

AAHL (Australian Animal Health Laboratory) (1999) Joint Pilchard Scientific Working Group Status report on research program: report to the Joint Pilchard Scientific Working Group. CSIRO AAHL, Geelong

Anderson RM, May RM (1979) Population biology of infectious diseases. Part 1. Nature 280:361-367

Bakke TA, Harris PD (1998) Diseases and parasites in wild Atlantic salmon (Salmo salar) populations. Can J Fish Aquat Sci 55:247-266

Baumgartner TR, Soutar A, Ferreira-Bartrina V (1992) Reconstruction of the history of Pacific sardine and northern anchovy populations over the past two millennia from sediments of the Santa Barbara Basin, California. Calif Coop Ocean Fish Invest Data Rep 33:24-40

Bayly G (2002) Tuna feed lotting. Aquac Mag 28(3):22-23

Bunce A, Norman FI (2000) Changes in the diet of Australian gannet (Morus serrator) in response to the 1998 mortality of pilchards (Sardinops sagax). Mar Freshw Res 51: 349-353

Dann P, Norman FI, Cullen JM, Neira FJ, Chiaradia A (2000) Mortality and breeding failure of little penguins, Eudyptula minor, in Victoria, 1995-96, following a widespread mortality of pilchard Sardinops sagax. Mar Freshw Res 51: 355-362

Daszak P, Cunningham AA, Hyatt AD (2000) Emerging infectious diseases of wildlife - threats to biodiversity and human health. Science 287:443-449

Dobson AP, May RM (1987) Effects of parasites on fish populations - theoretical aspects. Int J Parasitol 17:363-370

Dwyer G, Elkington JS (1993) Using simple models to predict virus epizootics in gypsy moth populations. J Anim Ecol 62:1-11

Ebert D (1998) Experimental evolution of parasites. Science 282:1432-1435

Edmunds JS, Fletcher WJ (1997) Stock discrimination of pilchards Sardinops sagax by stable isotope ratio analysis of otolith carbonate. Mar Ecol Prog Ser 152:241-247

Fisher RA (1932) The wave of advance of advantageous genes. Ann Eugenics 7:355-369

Fletcher WJ (1992) Use of a spatial model to provide initial estimates of stock size for a purse seine fishery on pilchards (Sardinops sagax neopilchardus) in Western Australia. Fish Res 14:41-57

Fletcher WJ, Jones B, Pearce AF, Hosja W (1997) Environmental and biological aspects of the mass mortality of pilchards (Autumn 1995) in Western Australia. Fisheries
Research Report 106, Fisheries Western Australia, Perth

Gaughan DJ (2002) Disease translocation across geographic boundaries must be recognized as a risk even in the absence of disease identification: the case with Australian Sardinops. Rev Fish Biol Fish 11:113-123

Gaughan DJ, Mitchell RW, Blight SJ (2000) Impact of mortality, possibly due to herpesvirus, on pilchards Sardinops sagax stocks along the south coast of Western Australia in 1998-99. Mar Freshw Res 51:601-612

Gaut AC (2001) Pilchard (Sardinops sagax) mortality events in Australia and related world events. Report of FRDC Project 99/227. Fisheries Research and Development Corporation, Canberra

Griffin DA, Thompson PA, Bax NJ, Bradford RW, Hallengraeff GM (1997) The 1995 mass mortality of pilchards: no role found for physical or biological oceanographic factors in Australia. Mar Freshw Res 48:27-42

Harvell CD, Kim K, Burkholder JM, Colwell RR and 9 others (1999) Emerging marine diseases - climatic links and anthropogenic factors. Science 285:1505-1510

Heath M, Zenitani H, Watanabe Y, Kimura R, Ishida M (1998) Modelling the dispersal of larval Japanese sardine, Sardinops melanostictus, by the Kuroshio Current in 1993 and 1994. Fish Oceanogr 7:335-346

Hedrick RP, Gilad O, Yun S, Spangenberg JV (2000) A herpesvirus associated with mass mortality of adult and juvenile koi, a strain of common carp. J Aquat Anim Health 12:44-57

Hill B (2002) National and international impacts of white spot disease of shrimps. Bull Eur Assoc Fish Pathol 22:58-65

Murray AG, Gaughan DJ (2003) Using an age-structured model to simulate the recovery of the Australian pilchard (Sardinops sagax) population following epidemic mass mortality. Fish Res 60:415-426

Murray AG, O'Callaghan M, Jones B (2000) Modelling the pilchard mass mortality events of 1995 and 1998/9. Report of FRDC Project 1999/225. Fisheries Research and Development Corporation, Canberra

Murray AG, O'Callaghan M, Jones B (2001a) Simple models of massive epidemics of herpesvirus in Australian (and New Zealand) pilchards. Environ Int 27:243-248

Murray AG, O'Callaghan M, Jones B (2001b) A model of transmission of a viral epidemic among schools within a shoal of pilchards. Ecol Model 144:245-251

Murray AG, Smith, RJ, Stagg RM (2002) Shipping and the spread of Infectious Salmon Anemia in Scottish aquaculture. Emerg Infect Dis 8:1-5

Neira FJ, Sporcic MI, Longmore AR (1999) Biology and fishery of pilchard, Sardinops sagax (Clupeidae), within a large south-eastern Australian bay. Mar Freshw Res 50: $43-55$

O'Callaghan M, Murray AG (2002) A tractable deterministic model with a realistic latent period for an epidemic in a linear habitat. J Math Biol 44:227-251

Patterson KR (1996) Modelling the impact of disease-induced mortality in an exploited population of the fungal parasite Icthyophonus hoferi in the North Sea herring (Clupea harengus). Can J Fish Aquat Sci 53:2870-2877

Smith P (1995) Pilchard deaths in New Zealand. Seafood New Zealand 3:26-29

Swinton J, Harwood J, Grenfell BT, Gilligan CA (1998) Persistence thresholds for phocine distemper virus in harbour seals Phoca vitulina metapopulations. J Anim Ecol 67: $54-68$

Torres AG, Martínez GF, Oliva JL (1984) Migraciones de la sardina español en el Pacifico Suroriental durante el fenómeno el Niño 1982-3 y en 1984. Invest Pesq 32:95-100 
Van der Lingen CD (1998) Nitrogen excretion and adsorption efficiencies of sardine Sardinops sagax fed phytoplankton and zooplankton diets. Mar Ecol Prog Ser 175:67-76

Ward TM, Staunton-Smith J (2002) Comparison of the spawning patterns and fisheries biology of the sardine, Sardinops sagax, in temperate South Australia and subtropical southern Queensland. Fish Res 56:37-49

Ward TM, Hoedt F, McLeay L, Dimmlich WF, Jackson G, Rodgers PJ, Jones K (2001a) Have recent mass mortalities of sardine, Sardinops sagax, facilitated an expansion in the distribution and abundance of anchovy, Engraulis australis, in South Australia? Mar Ecol Prog Ser 220: 241-251

Ward TM, Hoedt F, McLeay L, Dimmlich WF and 5 others (2001b) Effects of mass mortality on spawning biomass of

Editorial responsibility: Chris Baldock, Brisbane, Queensland, Australia
Sardinops sagax off South Australia. ICES J Mar Sci 211: 365-375

Whittington RJ, Jones BJ, Hine PM, Hyatt AD (1997) Epizootic mortality in the pilchard Sardinops sagax neopilchardus in Australia and New Zealand in 1995. I. Pathology and epizootiology. Dis Aquat Org 28:1-16

Yachi S, Kawasaki K, Shigesada N, Teremoto E (1989) Spatial patterns in propagating waves of fox rabies. Forma 4:3-12

Yardin MR, Dixon PI, Coyle T, Syahailatua A, Avramidis M (1998) Stock discrimination of Sardinops sagax in south eastern Australia: a collaborative investigation of the usage and stock assessment of baitfish in southern and eastern Australia with special reference to pilchards (Sardinops sagax). FRDC Report 1994/024. Fisheries Research and Development Corporation, Canberra, p 85-174

Submitted: December 15, 2000; Accepted: October 21, 2002 Proofs received from author(s): March 3, 2003 